\title{
Team-Based Care: Caring for the team under payment reform
}

\author{
Mark Linzer, $M D^{7}$, Becky R. Ford, PhD², Katherine F. Guthrie, MD³, and \\ Katherine Diaz Vickery, MD, MSc ${ }^{\top}$ (D)
}

${ }^{7}$ Hennepin Healthcare, Minneapolis, MN, USA; ${ }^{2}$ Hennepin Healthcare Research Institute, Minneapolis, MN, USA; ${ }^{3}$ Allina Health, United Family

Medicine, Saint Paul, MN, USA.

J Gen Intern Med 35(5):1600-2

DOI: $10.1007 / \mathrm{s} 11606-019-05452-2$

(c) Society of General Internal Medicine 2019

\section{INTRODUCTION}

The epidemic of burnout among clinicians is well documented $^{1}$. Less is known, however, about stress and burnout among staff ${ }^{2}$, particularly in safety net settings. As many organizations aim to reduce clinician burnout, and as an era of team-based care brings opportunity for sharing the care among multiple team members, the potential impact on work-life and wellness among other staff members remains to be determined. We examined burnout among all team members using data from a project on impact of payment reform on safety net health care clinicians, staff, and patients. We explored whether certain aspects of teamwork might be associated with lower burnout. The answers to these questions would provide the substrate for future studies to determine mechanisms to reduce burnout among all care team members.

\section{METHODS}

Interviews were conducted with staff and clinicians to design survey questions about awareness of payment reform. The single-item question on burnout, validated against the Maslach Burnout Inventory ${ }^{3}$, correlates predominantly with the emotional exhaustion component of burnout. Questions on collegial work environment were drawn from Jaen et al.'s work on adaptive reserve ${ }^{4}$.

Clinicians and staff were recruited at clinic-wide meetings. Copies of surveys were left for absent respondents with return envelopes. Denominators included all distributed surveys. Paper surveys were administered at

Prior presentations: None

Received July 15, 2019

Revised July 15, 2019

Accepted September 27, 2019

Published online October 24, 2019 three primary care clinic sites with majority low-income patients. Surveys were collected at two time points 11 months apart (2017 and 2018). We completed double data entry from paper surveys into a REDCap database; a senior research staff corrected inconsistencies.

Stata 15.1 was used to summarize survey responses using descriptive and bivariate statistics. Individuals were classified in their predominant role (if a nurse practitioner (NP) and a registered nurse ( $\mathrm{RN})$, they were considered an NP; if a physician and a resident, they were considered a resident). To protect confidentiality, groups with four or less individuals were relegated to an "other" category. Burnout, measured as a single item with five choices from not burned out and not stressed to highly burned out, was recoded as a binary variable (burned out, choices 3-5, vs not burned out, choice 1 or 2). Pearson's correlation coefficients were calculated for a correlation matrix for 6 questions about how clinicians contributed to a collegial environment ( $r \geq 0.3$ considered clinically meaningful). Institutional Review Boards at Allina Health and Hennepin Healthcare Research Institute approved this study while the University of Minnesota deemed the study exempt from requiring consent.

\section{RESULTS}

We approached 413 staff and clinicians and received 302 completed surveys ( $73 \%$ response rate). We found no significant differences between responses over the two time points, so we collapsed the data, removing respondents who took the survey in both years (final sample 136 staff and 116 clinicians). Figure 1 shows burnout rates ranging from $12.5 \%$ (for community health workers) to $85.7 \%$ (for licensed practical/vocational nurses). Attending physicians were in mid-range at $31.3 \%$, with comparable values for medical assistants (30.8\%) and slightly higher values for RNs (37.5\%). Resident physicians and social workers were toward the higher end of the range $(52.9 \%$ and $60 \%$, respectively). 


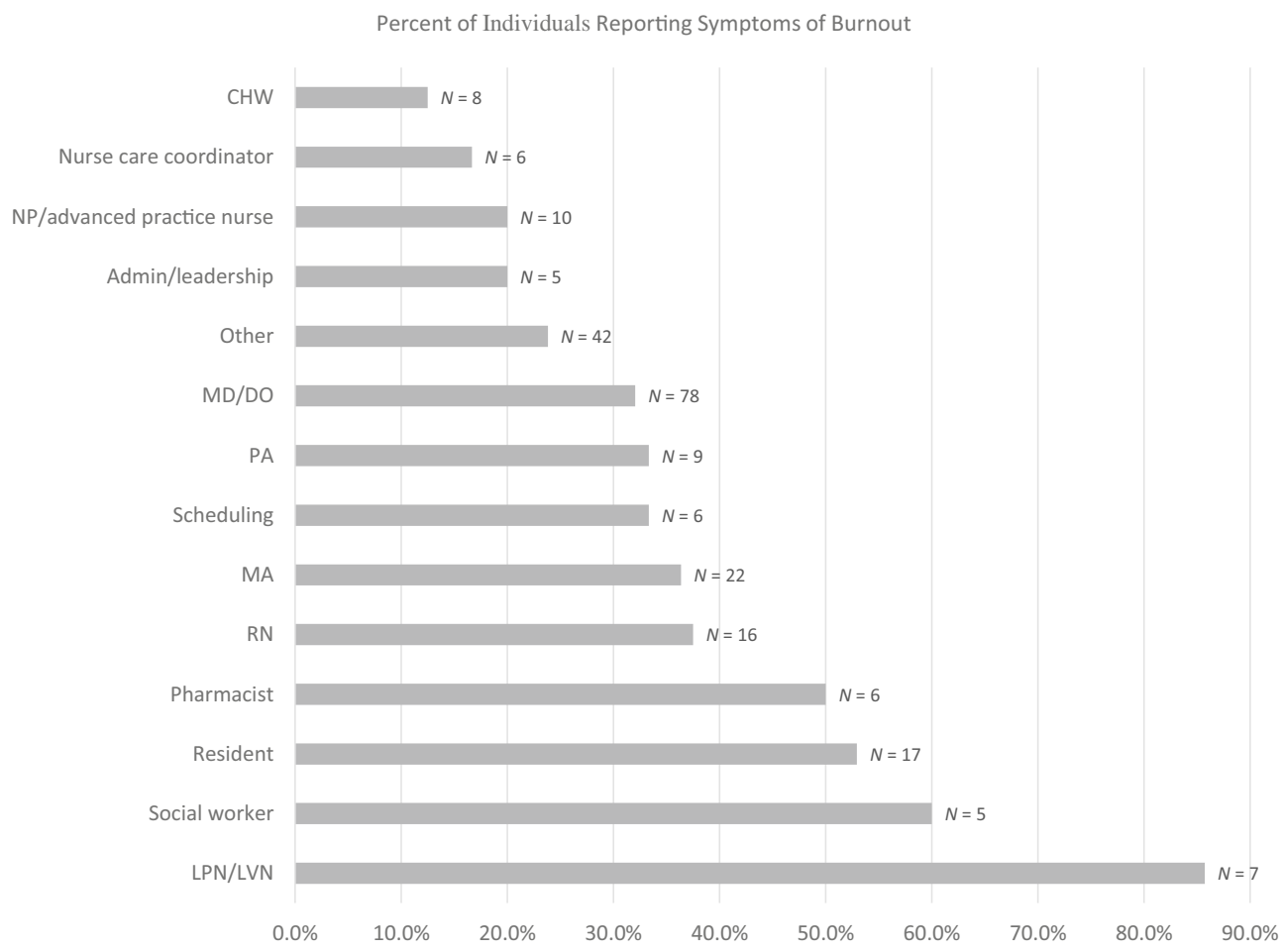

Figure 1 Burnout among staff and clinicians at 3 safety net clinics. "Other" includes psychologists, administration, office support, and participants who marked "other" for their role. CHW, community health worker; CNP, nurse practitioner; DO, doctor of osteopathy; LPN, licensed practical nurse; LVN, licensed vocational nurse; MA, medical assistant; MD, medical doctor; PA, physician assistant; RN, registered nurse. SW, social worker.

The correlation matrix between collegial work environment and burnout (Table 1) showed burnout was significantly associated with all questions. One question, asking if staff were encouraged to express alternative viewpoints, had a clinically meaningful correlation coefficient greater than 0.3 .

\section{DISCUSSION}

Among staff and clinicians in three safety net clinics, we found a wide range of burnout, from 12.5 to $87.5 \%$. While attending physician burnout was relatively common (31\%), burnout was higher among individuals in several other groups. This aligns with findings by Edwards et al. from a national study of small group practices ${ }^{2}$. In our study, lower burnout was seen when staff felt able to express alternative viewpoints.

There are several limitations to our study including small numbers of staff in several categories, and a single item measure of burnout with reduced sensitivity compared with other measures ${ }^{5}$. Strengths of the study include the high response rate, sampling at two points in time, and the use of

Table 1 Correlation Matrix for Questions on Staff Engagement and Burnout

\begin{tabular}{|c|c|c|c|c|c|c|c|}
\hline Item & $\begin{array}{l}\text { Lower } \\
\text { burnout }\end{array}$ & $\begin{array}{l}\text { Providers } \\
\text { open to staff } \\
\text { ideas }\end{array}$ & $\begin{array}{l}\text { Staff encouraged } \\
\text { to express own } \\
\text { views }\end{array}$ & $\begin{array}{l}\text { Staff afraid } \\
\text { to ask } \\
\text { questions }\end{array}$ & $\begin{array}{l}\text { Difficult to voice } \\
\text { disagreement }\end{array}$ & $\begin{array}{l}\text { My values } \\
\text { align with } \\
\text { leadership }\end{array}$ & $\begin{array}{l}\text { My values } \\
\text { align with co- } \\
\text { workers' }\end{array}$ \\
\hline $\begin{array}{l}\text { 5-point burnout } \\
\text { scale }\end{array}$ & 1.00 & & & & & & \\
\hline $\begin{array}{l}\text { Providers open to } \\
\text { staff ideas }\end{array}$ & $.14^{*}$ & 1.00 & & & & & \\
\hline $\begin{array}{l}\text { Staff encouraged } \\
\text { to express own } \\
\text { views }\end{array}$ & $.33 *$ & $.62 *$ & 1.00 & & & & \\
\hline $\begin{array}{l}\text { Staff afraid to ask } \\
\text { questions }\end{array}$ & $-.14^{*}$ & $-.43 *$ & $-.42 *$ & 1.00 & & & \\
\hline $\begin{array}{l}\text { Difficult to voice } \\
\text { disagreement }\end{array}$ & $-.24 *$ & $-.45^{*}$ & $-.56^{*}$ & $.65^{*}$ & 1.00 & & \\
\hline $\begin{array}{l}\text { My values align } \\
\text { with leadership }\end{array}$ & $.22 *$ & $.51 *$ & $.51 *$ & $-.45^{*}$ & $-.39 *$ & 1.00 & \\
\hline $\begin{array}{l}\text { My values align, } \\
\text { with co-workers' }\end{array}$ & $.18 *$ & $.42 *$ & $.36^{*}$ & $-.25^{*}$ & $-.33 *$ & $.47 *$ & 1.00 \\
\hline
\end{tabular}

$1=$ strongly agree, $5=$ strongly disagree. Burnout: $1=$ not burned out, $5=$ very burned out

$* p<.05$ 
validated metrics for burnout and staff engagement. While team-based care is a desirable goal ${ }^{6}$, monitoring work environment perceptions, along with clinician and staff burnout, would be prudent as change is undertaken.

Acknowledgments: We acknowledge Dr. Eileen Harwood's help in planning and development of the survey and support in data analyses.

Corresponding Author: Katherine Diaz Vickery, MD, MSc; Hennepin Healthcare, Minneapolis, MN, USA (e-mail: Katherine.Vickery@hcmed. org).

Funding Information This paper was supported by a grant (no. 73615) from the Robert Wood Johnson Foundation.

\section{Compliance with Ethical Standards:}

Institutional Review Boards at Allina Health and Hennepin Healthcare Research Institute approved this study while the University of Minnesota deemed the study exempt from requiring consent.

Conflict of Interest: Dr. Linzer works with AMA, Institute for Healthcare Improvement, and the American College of Physicians on clinician work-life improvements. Dr. Guthrie reports that her husband owns stock in Merck and Express Scripts. The other authors report no conflicts.

\section{REFERENCES}

1. Shanafelt TD, West CP, Sinsky C, et al. Changes in Burnout and Satisfaction With Work-Life Integration in Physicians and the General US Working Population Between 2011 and 2017. Mayo Clinic Proceedings. 2019:S0025619618309388. https://doi.org/10.1016/j.mayocp.2018.10. 023

2. Edwards ST, Marino M, Balasubramanian BA, et al. Burnout Among Physicians, Advanced Practice Clinicians and Staff in Smaller Primary Care Practices. J Gen Intern Med. 2018;33(12):2138-2146. https://doi. org/10.1007/s11606-018-4679-0

3. Rohland BM, Kruse GR, Rohrer JE. Validation of a single-item measure of burnout against the Maslach Burnout Inventory among physicians. Stress and Health. 2004;20(2):75-79. https://doi.org/10.1002/smi.1002

4. Jaen CR, Crabtree BF, Palmer RF, et al. Methods for Evaluating Practice Change Toward a Patient-Centered Medical Home. The Annals of Family Medicine. 2010;8(Suppl_1):S9-S20. https://doi.org/10.1370/afm.1108

5. Olson K, Sinsky C, Rinne ST, et al. Cross-sectional survey of workplace stressors associated with physician burnout measured by the Mini- $Z$ and the Maslach Burnout Inventory. Stress and Health. 2019;35(2):157-175. https://doi.org/10.1002/smi.2849

6. Ghorob A, Bodenheimer T. Sharing the Care to Improve Access to Primary Care. N Engl J Med. 2012;366(21):1955-1957. https://doi.org/ 10.1056/NEJMp1202775

Publisher's Note Springer Nature remains neutral with regard to jurisdictional claims in published maps and institutional affiliations. 